\title{
ARCHITECTURE AND NEW ONTOLOGIES
}

\author{
A B S T R A C T
}

The history of architecture and contemporary architectural discussion show that the encounters of architecture and philosophy are neither rare nor exceptional. The central thesis of this article is that today architecture and philosophy are connected in a way that goes beyond the variety of their interdisciplinary co-operation. The two domains of thought are connected in a more "existential" sense: they both need to address certain issues that concern the conditions of the possibility of their future existence. The article focuses on two such issues: it seeks to demonstrate in what way the existence of architecture and philosophy depends, on one hand, on the ancient alternative between the logic of the One and the logic of the Multiple; and on the other hand, on the concept of the indiscernability of thought and act. In so doing it draws on the Lacanian triad of the symbolic, the imaginary and the real. 
In this paper I will take part as a philosopher and, as I would like to say from the very outset, not as a philosopher who specializes in questions of culture, let alone architecture; but as a philosopher whose concern is philosophy and its conditions in the contemporary world. If I still dare accept the invitation to discuss the issue of the possibility of the project of architecture with architects, I do so because the question which summarized the themequestion of the Project Architecture conference, whether "architecture can still be practiced as architecture today" - if in this sentence "architecture" is replaced with "philosophy" - is also relevant for philosophy. The possibility of such replacement stands as testimony to the fact that today architecture and philosophy are connected in a way that exceeds the various possible forms of their interdisciplinary co-operation. They are connected in a more "existential" sense. Let me explain what I mean by this "existential" connection between architecture and philosophy.

Firstly, they are connected existentially as they exist and function in the same world, in the historical, political and intellectual situation determined by the dynamics of the late capitalism. Further on, architecture and philosophy are connected existentially because of their inner, structural logic - and regardless of the great differences between them - they are both a type of thinking and work which I can designate under the term of creative practice. I will speak more about the creativity component in the continuation. And finally they are existentially connected in what is for both disciplines on the agenda today, as it were, what is a necessary condition for the possibility of their existence in the world of globalized capitalism: not only do they have to insist on working as a process of creation, but they also have to make sure that as creative practices they also appear and affirm themselves within this world. For not only does the future existence of these fields of thought depend on the courage, strength and ability of affirming themselves as such; but also, in this time of global disorientation, when capitalism seems our only destiny, the insistence on this affirmation opens up the possibility of local points of orientation. One of the big questions of our time, it would appear, is whether we can find a way to resist the One of the closed totality of the capitalist order. My thesis is that the processes of creative work are according to the logic which tears up and interrupts the logic of either the instrumental or the dialogical-communicational ways of working that have been cultivated by capitalism. Naturally, the logic of the processes of creation alone does not offer an answer to the issues of capitalism. If we insist on it, however, it offers at least a local possibility of orientation. At the same time, in this insistence there is also a delineated possibility of a militant alliance - and not only between architecture and philosophy. 
I have mentioned earlier that the very existence of architecture and philosophy is under the threat today. I should be a bit more precise. Naturally, architecture and philosophy can exist and will also exist within the framework of the globalized capitalism. Indeed, they can both thrive within this framework. The problem, therefore, is not in the actual possibility of existence of architecture and philosophy, but in something else. This can be formulated with the help of the famous Robespierre's question - "Citizens, would you want a revolution without a revolution?" Architects and philosophers could well ask themselves a similar question today, being, "Architects, would you want architecture without architecture? Philosophers, would you want philosophy without philosophy?"

But in what sense can we even speak about a creative practice today? The notion of creativity and creation has for us become thoroughly problematic along the way. On one hand, it is anachronistic: it belongs, so it would seem, to some other time. It would be difficult to accept today that which, traditionally speaking, is its ingredient: the instance of the great Creator embodied, for instance, in the figure of "architectus ingenio" from the seventeenth century, who represents a kind of a mental centre of the process of creation. ${ }^{1}$ On the other hand, however, the notion of creativity is all too contemporary, for since the 1980s it has represented a solid core of political and economic strategies and has served, in the form of so called "creative industries" (among which architecture is listed), as one of the driving forces of both the European and other economies.

I will try to explain my own understanding of the terms "creation" and "creative practice", as I use them in this essay, in two steps. First I will use the conceptual apparatus of contemporary philosophy and of the psychoanalysis of Jacques Lacan. Then I will try to show in rough outlines, using an example from contemporary architectural theory - it should be noted that this example is taken arbitrarily - that architecture, in its own language and with its own material, deals with the same problems which contemporary philosophy and psychoanalysis deal in their respective fields with.

\section{THE STONE, THE TRIAD, AND THE KNOT}

I will divide a more philosophical part of this into two parts. Let me begin with the well known thesis of Martin Heidegger on what is central to human creation; more precisely, when does that which is created bear the stamp of a human presence. In his seminar The Ethics of Psychoanalysis ${ }^{2}$ Lacan relates to 
Heidegger's thinking. In his text "The Thing" from 1950 Heidegger takes a potter's jug as a paradigmatic example of a human creation. ${ }^{3}$ On the one hand a jug is one of many human utensils; it has, as Lacan notes, always been there, it is perhaps the most primordial feature of human inventiveness and industry, it allows us to affirm unambiguously a human presence wherever we find it. ${ }^{4}$ The jug consists of a bottom and the sides, but, as Heidegger emphasizes, this is not what is created. What is created when a potter shapes the vase is the void. "For it, in it and out of it", as Heidegger says, a potter "forms the clay into the form". ${ }^{5}$ A potter who creates the jug creates it starting with a hole, so to speak, ex nihilo. In Lacan's words, a jug is the object made to represent the existence of the void at the centre of the real or the Thing - the Thing that marks the irreducible presence of a man in the world - and this void presents itself as nihil, as nothing. Heidegger and Lacan could briefly be summarized thus: the human presence in the natural Universe is marked by a void; a human being introduces a Nothing into nature, and then from this Nothing creates his own world. From the point of view of this created Nothing it could perhaps be said that the characteristic feature of architecture is not so much that it places itself in space, but that it primarily creates space; more precisely, architecture creates space for architecture. Another thing of course is whether an architect is also able to design this space as a space for living, as a space for dwelling worthy of a human being.

And in my view it could be said that the architectural equivalent of a potter's vase is the stone that, as Vittorio Gregotti puts it, a man placed on the ground to recognize a specific site in the midst of an unknown universe. ${ }^{6}$ In my view, placing this stone is not an appropriation of space, but the stone literally creates the space where architecture will take place, architecture as the mark or sign of a human dwelling.

Precisely, Gregotti's stone as a kind of a primordial materialization of an architectural act, also attracts our attention to that which is essential about human creation. This creation is, as I said, original creation of Nothing and creation from Nothing. We should not overlook the fact, however, that this Nothing is not simply of nothing, if I may say so. Nothing, with which a human being marks his presence in the natural universe, has a paradoxical status: it is Nothing which is Something. It is not simply a void. It is a void which is here, a place where so to speak, there is full of void. It is a Nothing which has some positive, material presence. But this materiality, even if it is present in the midst of the world, does not correspond to any materiality of this world. This is a materiality with a specific ontological status. 
This brings us to another, more philosophical part of my lecture, to Lacan's triad of the symbolic, the imaginary and the real. I will begin with a short presentation of this triad with a remark which is associated with the title of my lecture "Architecture and New Ontologies". With new ontologies I mean the philosophy of Alain Badiou and Lacan's psychoanalysis, and the actual term "new ontologies" can be explained thus: from a traditional point of view in philosophy - but also on the level of everyday consciousness - we have to deal with the scheme of two, with a being and appearance as its opposite; or also, with reality and its representation, with things and words. This scheme of two in the new ontologies changes into the scheme of three: instead of two entities, and this or that kind of dialectics of their inter-connection, we have now, if I use Lacan's triad, a knot of three: the triad of the symbolic, the imaginary and the real.

Today's absolute hegemony of capitalism also opens up the ancient alternative of One or Multiple as the two most abstract and fundamental determinations of being. With regard to this alternative new ontologies decide in favor of the Multiple. However, the multiplicity they affirm is an inconsistent, untotalizable multiplicity. An affirmation of a multiplicity does not simply mean that there is not One, and that, instead, there is only multiplicity. A multiplicity means that there is One which lacks - the lack of One is constitutive for a multiplicity. Only on the basis of this lacking can a multiplicity constitute itself. However, as something belongs to it which is lacking, it constitutes itself as an inconsistent multiplicity, as a multiplicity which is not-All. And creativity is not simply an affirmation of a Multiple against One. Rather, multiplicity is affirmed by the affirmation of that One which is lacking in it. $^{7}$

In this sense, today, forty years following May of 1968, we could remain faithful to the spirit of 68 which is also expressed in Hans Hollein's manifesto "Alles ist Architektur", "All is Architecture" - and "Alle sind Architekten", "Everyone is an architect" as Hollein concludes his manifesto - only if we translate this manifesto into "Architecture is not-All" and "An architect is everyone who is able to think and practice this not-All of architecture". The conclusion, that architecture is not-All, we already arrive to if we carry out an essential implication of the declaration "All is Architecture". Namely, if we do not want to fail Popper's criterion of falsification, which says that it is always possible to discover an element which could not be included in a multiplicity, in our case in the multiplicity of architecture - that it is always possible that an element appears which cannot be declared as an architectural element - then we should understand the 
statement "All is Architecture" in the following way: All is architecture, also that, which is not architecture. And this non-architectural element, which works now as a constituent part of architecture, prevents architecture from establishing itself as All, as an enclosed entity.

Lacan's triad of the symbolic, imaginary and real represents also such an inconsistent multiplicity, which I will now try to explain briefly. These three components if I may say so, are three fundamental Lacanian categories or principles of classification according to which different objects can be arranged.

With this triad we have all. With it, we have the world, or, to put it differently, the triad enables us to access our reality; it is by means of this triad that there can be something like a reality for us. And the triad is also all that we have. Firstly, this reality is constituted and structured by a symbolic structure, S. Secondly, we live this world, this reality in an always specific way, in the way we imagine it; that is, in an imaginary way, I. And thirdly, to say as Lacan does, that our reality is nothing but a montage of the symbolic structure and imaginary representation, is to say that in this reality of two something constitutively lacks, indeed, something which, for this reality to be possible at all, necessarily falls out: namely the real, $R$. Something which exceeds it or which is missing in it, an immanent exception, the real as the immanent exteriority of reality, also belongs to a symbolic-imaginary reality.

However, this triad isn't about three elements, symbols, which simply co-exist. On the contrary, the Lacanian triad constitutes a knot. As I mentioned earlier, the symbolically structured reality is always organized around something which falls out of it. It is organized around an exclusion, its condition of possibility is that which falls out of it - that which, with the emergence of the symbolic, is impossible. However, this impossible is something very real. Without it there would be no symbolically structured reality of the world. The symbolic structure therefore isn't possible with the real; nor, however, is it possible without the real.

From the very beginning we are dealing with the One, the symbolic, which is split into Two as it is accompanied, like by a shadow, by its immanent exteriority, the real as its immanent exception. To this inconsistent One-inconsistent as it is always already Two - the third instance, the imaginary is added. This adding has a specific function. The imaginary is not only the way, as I said earlier, in which we live the symbolically ordered reality. It is rather always a specific manner also in which the falling-out of the real is thought and staged in the reality. This 
falling-out, for instance, can be denied or suppressed, it can also be semiacknowledged. However, this immanent exception of the real - the fact that within reality as its moment something works which is radically heterogeneous to it - it can also arise as that which is crucial. A creation is connected precisely to this possibility.

In other words, in the knot of the symbolic, imaginary and real, the creation, too, is knotted. And it is knotted in the way which prevents its appropriation from the side of the capitalist discourse. The process of creation is nothing but this knotting of a knot, in which the instances of the symbolic, imaginary and real are connected in such way that in the midst of reality a trace of the real is affirmed, a trace of that which interrupts reality, as it lacks or it exceeds this reality. Where for the situational logic there is only two - reality and its various representations - for the logic of the real there is a reality at work which is torn in itself. It is torn as it is organized around an immanent exception, around a moment, which makes it inconsistent, open to the possibility of something which is trans-situational and which is, precisely because of that universallyemancipatory, as it potentially addresses us all.

We have a scheme that differs radically not only from the traditional philosophical pairs - being / appearance, reality / representation, things / words - but also from our everyday perception of reality. Here we have always to do with two, with something given, substantial, and with that which somehow expresses this substantial givenness. The relationship between the two is one of representation. And regardless of all the problems associated with the question, how to think about the relationship between the expression and the expressed, one could say that this scheme presents to us a homogenous totality, in and of itself enclosed - which is not subject to and does not recognize any radical interruptions, instances of disruption, or instances of impossibility. With the real, however, an instance which does not have its place in the homogenous world of the symbolic and the imaginary, is brought into this world as its constituent part, an instance which is by definition out of place and unplaceable and which, as such, interrupts the normal functioning of the situation. In the situation, which is a network of different possibilities, it also affirms that which for this situation is its impossible. In this sense the real is trans-situational and cut out of the time which determines the situation.

THE CASTLE, THE DiLEMMA, AND THE ETERNAL

In the second step, in a very brief and fragmentary way, I will comment on an article by Michael Hays, called "Critical Architecture: Between Culture and Form". 9 
This article holds special interest for me as, in my view, the scheme of three could help us respond to the dilemma that Hays's article addresses. But I am also interested in this article as it develops a certain understanding of architecture which brings architecture very close to the process of creation, as this process can be considered on the basis of the Lacan's triad.

Hays's article addresses the autonomy - heteronomy dilemma of architecture. Just to remind ourselves, Hays rejects the understanding of architecture as - if I use his words - an autonomous system of formal categories and operations free of history and circumstance. As well as the understanding of architecture as something which is "essentially an epiphenomenon, dependent on socioeconomic, political and technological processes". ${ }^{10}$ Instead - referring to the architecture of Mies van der Rohe - he suggests as an irreducibly architectural realm a place between: between the existing cultural values and the autonomy of an abstract formal system; in short, between culture and form. In constructing this "place between" there lies the entire strength of Hays's argumentation. But, here, too, lies all of its weakness. That "between" should not be understood as a kind of a dialectical synthesis, is clear. But if Hays describes "between" as that which is not one nor the other, he does not go on to identify what this "nor one nor the other" is; what is, according to its ontological status, the corporality of a building, which is neither a representation of external forces, nor can it be reduced to an idealized realm of autonomous form.

In my view, however, we could overcome the conceptual indetermination of this "between" by claiming that "between" is something which in the double pure interiority of architecture vs. architecture as a sign of something exterior - simply does not have its place. "Between" as that irreducible place of architecture is that which precisely is not "between": it is what the position of autonomy and the position of heteronomy together exclude, suppress, reject. Would not it be thus most appropriate to say that this "between" has the status and function of the real? Only in this way do a number of Hays's brilliant yet isolated thoughts become connected. I am quoting here just a few of them: ${ }^{11}$ for example, that Mies's architecture transforms the empirical, both cultural and formal, conditions of its formation into the materiality of an irreducibly architectural object (22); that an object displaces that what would have been in its place (22); that it is something which is in its actual existence continually being produced (24); that the architectural reality takes its place alongside the real world (25); that an architectural object is outside and inside at the same time, a participant in the world and yet disjunctive with it, that it tears a cleft in the continuous surface of reality (25); that it introduces the contingent to the reality, 
the unpredictable and the inexplicable (26). And if Hays quotes Stanford Anderson's claim that an architectural artifact is nothing but "a winning of reality" (25), then we could reproach him only for not drawing all of the relevant consequences from this statement: in particular, that in this winning we do not find a greater quantity of reality at work, but a kind of a different ontological quality of reality.

The reality at stake here is the real; in short, a kind of reality which is radically heterogeneous in relation to the "ordinary" reality of the world. An architectural object is that which pierces a hole in the given architectural knowledge as well as in the social and cultural body. Architecture works in such way that it first opens an empty place in which an architectural object, with its specific materiality, can then place itself. Precisely in the construction of an architectural object, in "a building as an example of architecture" 12 , if I use a term from Petra Čeferin, architecture manifests itself as a process of creation, as a creative activity sui generis. This activity, on the one hand, pierces through its formal as well as its situational determination. On the other hand, however, the corporeality of an architectural object works in the middle of reality as that which shows that this reality is inconsistent, open, contingent, that it is in no way the only thing that is possible.

In this sense the following analogy could be put forward: what is for Lacan's psychoanalysis the problem of the real - that is, the problem of a Thing, which is radically heterogeneous in relation to all other things of our reality but is precisely as such crucial for reality - is for architecture the problem of specificity of various forms of architecture's embodiment, the problem of a specific and irreducible materiality of an architectural object. After all, an architectural object is precisely that place which decides whether architecture is only knowledge and skill, or is a process of creation; which is to say, the articulation of an object which works in the middle of reality as its immanent and generic exception.

At this point, where a serious analysis of the architectural object should begin, I will bring my essay to a conclusion instead, by turning to a famous painting by René Magritte: "The Castle in the Pyrenees" (1959). Against the background of this painting, I will al least try to outline that what I have termed "the irreducible materiality of the architectural object".

What in fact is an architectural object? It is One which is always already Two. It is a constructed building, ourcastleat the top ofarock, that is to say, it is an object which 
is both materially and formally determined by the space and time of its making. The fact that this object-the castle is at the same time also something else, an architectural object, however, is evidenced by its inseparability from the rock. It is precisely in this rock, I will argue, that we can find the thingness of the building as an architectural object, or also, the materiality of its architectureness. This materiality, of course, is inseparable from the building itself, our castle. It exists, it is here, only because of this concrete, materialsensuous object which was constructed by architecture. The materiality of the rock does not exist without this building. But why then is the rock bigger than the constructed object? It is bigger because - if I turn to the words of Kenneth Frampton which he concludes his essay "Rappel à l'Ordre" with - it is "timebound", its materiality is "timeless". In other words, if I again use Frampton's formulation, it is "excised from the continuity of time", ${ }^{13}$ that is, it is eternal. The materiality of an architectural object is, so to speak, transversal in relation to time and it is always here. It is here, present - on condition that someone, an architect, a spectator, anybody really sees this castle here as an example of good architecture. If and when somebody sees this concrete building here, which has some temporal duration, as an object that maintains its always topical creative power, he or she at the same time brings into existence this trans-temporal rock of the architectureness. And it is precisely because the eternity of this rock comes into being only when it is locally decided that the entire construction here is suspended in the air.

Before I conclude, I would like to go back briefly to the question evoked at the beginning: "Architects, would you want architecture without architecture?" What does it mean to want architecture with architecture? When, indeed, can we see in architecture that there is also something of architecture? The answer is obvious: then, when we want to see. I will try to explain this answer in some more detail.

Let me point out two things. Firstly, the desire evoked in this question is not a psychological category. Rather, it is inseparable from architecture, it is, strictly speaking, an architectural category. It is a desire for architecture in a twofold sense: on the one hand, only this desire provides architecture with its truly architectural character; on the other hand it is itself, as desire, determined by architecture.

And this means, secondly, that only those who desire their desire for architecture are capable of practicing architecture with architecture. Thus the question: "Architects, would you want architecture without architecture?" could also be 
rephrased into the question: "Would you want a desire without a true desire?" Or, also: "Do you truly want, what you desire?" Naturally, here I draw on Lacan and his imperative according to which "it is as desire's object a" that the subject "is called to be reborn in order to know if he wants what he desires...". ${ }^{14}$

I would like to stress what I consider to be crucial here: that the operation of wanting one's desire is an operation of the de-psychologisation of desire. And de-psychologised desire is a conjunction of thought and affect; more precisely, it is a thought which is affected, that is, affected, struck by the "architectural thing". This is precisely why the practice of architecture, regardless of all personal engagement of an architect in it, is an impersonal act. In this sense an architect if again I use Lacan's words, is a "headless subject" of the drive. ${ }^{15} \mathrm{He}$ or she is a headless subject because he / she is in the service of the "architectural thing", which motivates and guides him / her.

This also explains why a desire for architecture cannot be separated from a desire to see architecture. The answer to the question, when can we see in architecture that there is also something of architecture, therefore is: only then, when an architect desires to see. That is to say, when he or she participates in the process of looking with his or her desire to see. The question "Architects, would you want architecture without architecture?" can then be reformulated as follows: "Architects would you want to see architecture without a desire to see?"

The desire to see, however, is always already a desire to make visible, to stage that which we want to see. A true architecture, that is, an architecture with architecture, is that architecture which we can see because we desire to make it visible - simply put, which we desire to make. It is the architecture which can be seen, because the desire to see is after all nothing but the inseparability of thought and action. With the question of the inseparability of thought and action, however, we already enter the territory of another theme. And so I will conclude with the following answer to the question, how we can see that, in architecture, there is something of architecture. The answer is: by thinking and practicing architecture. 
NOTES

N.B.

This paper was originally published in Project Architecture. Creative Practice in the Time of Global Capitalism, ed. J. Bickert, Architecture Museum, Ljubljana2010.

"The superintending architect, a man of ideas, familiar with the history of architecture, skilled in geometry and drawing techniques, and with the a sufficient knowledge of astronomy, law, medicines, optics and so on", quoted in A. Forty, Words and Buildings. A Vocabulary of Modern Architecture, Introduction, Thames\&Hudson, New York 2000, p 11. Forty's reference is the book by John Evelyn, Account of Architects, 1664.

J. Lacan, The Ethics of Psychoanalysis 1950-1960, Book VII, ed. by J.-A. Miller, transl. with notes by D. Porter, Routledge, London 1992.

In: M. Heidegger, Poetry, Language, Thought, transl. and introd. by A. Hofstadter, Harpers Collins Publisher, New York 2001, p $161 \mathrm{ff}$.

J. Lacan, op. cit., p 120.

M. Heidegger, op. cit., p 167.

V. Gregotti, "Lecture at the New York Architectural League", Section A., no.1, February / March 1983.

A simplified example of such a multiplicity is a society. A society isn't possible without the instance of authority. In modern societies this authority, which is a constituent part of the society, doesn't belong to anybody. The place of the authority is empty; as a result of elections it can be only temporarily taken. In other words, in the societal multiplicity the authority is present as that One which is lacking.

H. Hollein, "Alles ist Architektur”, Bau, Schrift für Architektur und Städtebau, 1/2, 23 $3^{\text {rd }}$ year, Vienna 1968, pp 1-32.

M. K. Hays, "Critical Architecture: Between Culture and Form”, in: Perspecta, Vol. 21., 1984, pp 14-29.

Ibid., p 16.

All quotations in the brackets refer to the pages in the quoted Hays article.

Cf. P. Čeferin, "Project Architecture", p??? of this book.

K. Frampton, "Rappel à' l'Ordre: The Case for the Tectonic", Labour, Work and Architecture. Collected Essays on Architecture and Design, Phaidon, London / New York 2002, p 103.

$C f$. "Remarks on Daniel Lagache's Presentation: 'Psychoanalysis and Personality Structure", in. J. Lacan, Écrits, transl. by B. Fink (in coll. With H. Fink and R.Grigg), W.W. Norton Company, New York - London 2002, p 571/2.

Cf. J. Lacan, The Four Fundamental Concepts of Psycho-Analysis, ed. by J.-A. Miller, transl. by A. Sheridan, Introduction by D. Macey, Penguin Books, London 1994, p 181. 